\title{
Incidence and mortality rate of cervix cancer in Iran from 1990 to 2016: A systematic review and meta-analysis
}

\author{
Shirin Riahi, ${ }^{a}$ Ali Mohammad Mokhtari, ${ }^{b}$ Mouhebat Vali, Elham Abdzadeh, ${ }^{d}$ Shokrollah Mohseni, \\ Hamid Salehiniya ${ }^{\mathrm{fg}}$ and Soheil Hassanipour ${ }^{\mathrm{h}}$
}

\author{
aNon-communicable Diseases Research Center, Alborz University of Medical Sciences, Karaj, Iran. \\ bSocial Determinants of Health Research Center, Mashhad University of Medical Sciences, Mashhad, Iran. \\ cStudent Research Committee, Shiraz University of Medical Sciences, Shiraz, Iran. \\ dDepartment of Biology, Faculty of Science, University of Guilan, Rasht, Iran. \\ eSocial Determinants in Health Promotion Research Center, Hormozgan Health Institute, Hormozgan University of Medical Sciences, Bandar Abbas, Iran. \\ Zabol University of Medical Sciences, Zabol, Iran. \\ פDepartment of Epidemiology and Biostatistics, Tehran University of medical sciences, Tehran, Iran. \\ hGastrointestinal and Liver Diseases Research Center, Guilan University of Medical Sciences, Rasht, Iran. \\ *Correspondence to Soheil Hassanipour (email: Soheil.epid@gmail.com). \\ (Submitted: 21 October 2018 - Revised version received: 29 October 2018 - Accepted: 11 November 2018 - Published online: 26 February 2019)
}

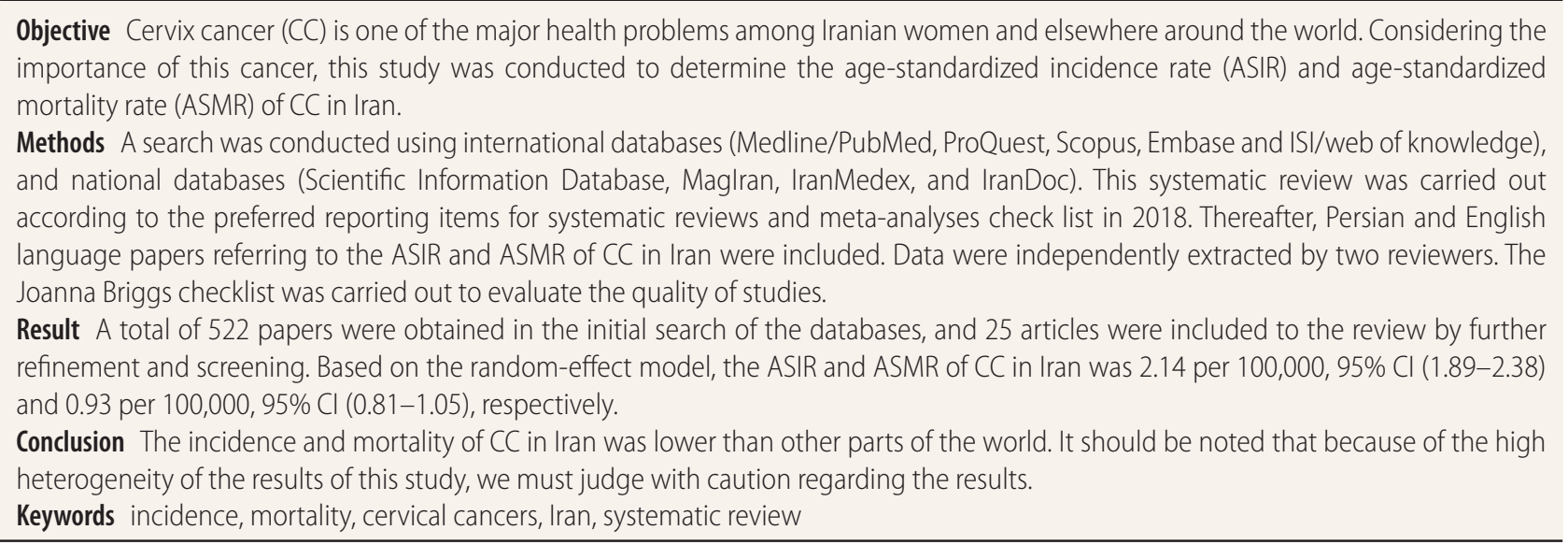

\section{Introduction}

Today, cancer is one of the major health problems in Iran and in the rest of the world. ${ }^{1}$ The findings revealed that female genital cancers are the fourth most common malignancy in women. ${ }^{2,3}$ The incidence rate and prevalence of female genital cancers in various parts of the world is different. According to GLOBOCAN 2012, the incidence of age-related cervical cancer is 13.1 per 100000 and the standardized death rate is 6.9 per 100000 population. ${ }^{1}$ Cervix cancer (CC) is the seventh common among all other one, although in some parts of the world, such as Africa and South Asia, it is the first cause of cancer deaths. ${ }^{4,5}$ Among women in developing countries, this malignancy is one of the most important causes of female mortality and after breast cancer, it is the most frequent malignancy. ${ }^{6,7} \mathrm{CC}$ is not only the most common and prevalent malignancy among women in many developing countries, but also the social significance of the disease becomes more pronounced because of their younger age at death. ${ }^{8}$ Certainly, for some reasons, such as having a long period before the invasion, the existence of a screening program and the availability of appropriate treatment for primary lesions, this cancer can be prevented. ${ }^{9}$ In epidemiology and demography, most rates, such as the incidence, prevalence, and morbidity are strongly related to age. This is also true for many types of cancers. For different purposes, age-specific comparisons may be helpful. However, the comparison of crude age-specific rates over time and between populations may be highly misleading if the age composition of the compared population is different. ${ }^{10}$ For this reason, standardization is important when comparing disease rates between regions or countries and is widely used in cancer research. Age-standardized rate is a summary amount that will be observed for a population, provided that the age-specific rate of the population and the age composition of the population should be considered the same as the reference population (standard population). ${ }^{11}$ Generally, genital cancers are one of the most common causes of female mortality. Detection and timely treatment of these cancers can increase women's longevity. ${ }^{12}$ The first step is to control the burden of disease related to cancers in any community, recognizing their status in the population, as well as collecting information about the incidence, type, and location of cancers. ${ }^{13}$ Although organized review studies have been conducted on some of the risk factors for these cancers ${ }^{14}$ a comprehensive, structured review of ASIR and ASMR of CC, has not yet been conducted in Iran. Therefore, considering the above-mentioned points and the importance of this cancer, this study was conducted with the aim of estimating the standardized incidence and mortality rate of cervix cancer in Iran.

\section{Materials and Methods}

This study is a systematic and meta-analysis of the incidence and mortality of CC in Iran which was designed in 2018. 
The methodology of this study is based on the preferred reporting items for systematic reviews and meta-analysis (PRISMA) checklist. ${ }^{15}$

\section{Search Strategy}

In September 2018, the researchers examined six international databases Medline/PubMed, ProQuest, Scopus, Embase, ScienceDirect and Google Scholar, and four Iranian sites SID, MagIran, IranMedex and IranDoc. Selected keywords for international databases include "Gynecological cancer", "Female genital cancer", "Cervix”, "Cervix cancer", Cervix neoplasms, "Cervix tumor", "Cancer of cervix", "Neoplasms of the cervix", "Incidence", "Epidemiology", "Occurrence", and "Iran". The collected data entered the EndNote X7 software, and duplicate articles were automatically deleted. It is worth to mention here that two researchers explored articles individually.

\section{Inclusion and Exclusion Criteria}

Studies that clearly reported the incidence and mortality rate of CC in Iran were analyzed. On the other hand, the studies that reported the incidence with insufficient sample sizes, as well as posters presented in the conferences were excluded.

\section{Quality Assessment}

To check and control the quality of the articles, the checklist used by the Joanna Briggs Institute was used. This tool consists of nine questions that are categorized as "Yes, No, Unclear, and Not Used." The purpose of this tool is to assess the methodological quality of studies, and ways to achieve and identify the errors in studies, design, implementation, and analysis of data. The quality assessment results were presented in Table 1.

\section{Screening Studies}

Initial research was conducted by two people (first and second authors). Screening of studies, extraction of results, and also the quality control of articles was evaluated separately by two individuals (first and second authors). If there was no match between the two, the supervisor of the team (responsible author) would announce the final comment on that article.

\section{Statistical Analysis}

The heterogeneity of the studies was evaluated by Cochran test (with significance $<0.1$ ) and its composition using statistics $I^{2}$. In the case of heterogeneity, the random effects model was used with the inverse-variance method and in the absence of

\section{Table 1. JBI critical appraisal checklist applied for included studies in the systematic review}

\begin{tabular}{|c|c|c|c|c|c|c|c|c|c|}
\hline Author name (year) & Q. 1 & Q.2 & Q.3 & Q.4 & Q.5 & Q.6 & Q.7 & Q.8 & Q.9 \\
\hline Saalabian (1990) & Yes & Yes & Yes & Yes & Yes & Yes & Yes & No & Yes \\
\hline Sadjadi (2003) & No & Yes & Yes & Unclear & Yes & Yes & Yes & Yes & No \\
\hline Babai (2005) & Yes & Yes & Yes & Yes & Yes & No & Yes & No & Yes \\
\hline Sadjadi (2005) & Yes & Yes & Yes & Yes & Yes & Yes & Yes & Yes & No \\
\hline Fallah (2007) & Yes & No & No & Unclear & Yes & Yes & No & Yes & Yes \\
\hline Sadjadi (2007) & Yes & Yes & Yes & Unclear & Yes & Yes & No & No & Yes \\
\hline Mehrabani (2008) & Yes & Yes & Yes & Yes & Yes & No & Yes & No & Unclear \\
\hline Somi (2008) & Yes & Yes & Yes & Yes & Yes & No & Yes & No & Unclear \\
\hline Mohagheghi (2009) & Yes & Yes & Yes & Yes & Yes & No & Yes & No & Unclear \\
\hline Mousavi (2009) & Yes & Yes & Yes & Yes & Yes & No & Yes & No & Yes \\
\hline Babaei (2009) & Yes & Yes & Yes & Yes & Yes & No & Yes & Yes & Yes \\
\hline Masoompour (2011) & Yes & Yes & Yes & Yes & Yes & No & Yes & No & Yes \\
\hline Almasi (2012) & Yes & Yes & Yes & Yes & Yes & No & Yes & No & Yes \\
\hline Fateh (2013) & Yes & Yes & Yes & Yes & No & No & Yes & No & Yes \\
\hline Khorasanizadeh (2013) & Yes & Yes & Yes & Yes & No & No & Yes & No & Yes \\
\hline Arab (2014) & Yes & Yes & Yes & Yes & No & No & Yes & No & Yes \\
\hline Arab (2014) & Yes & Yes & Yes & Yes & Yes & No & Yes & No & Unclear \\
\hline Taheri (2014) & Yes & Yes & Yes & Yes & Yes & No & Yes & No & Unclear \\
\hline Sharifian (2014) & Yes & Yes & No & Yes & Yes & No & Yes & No & Unclear \\
\hline Rahimi (2015) & Yes & Yes & No & Yes & Yes & No & Yes & Yes & No \\
\hline Masoompour (2016) & Yes & Yes & Yes & Yes & Yes & No & Yes & Yes & No \\
\hline Almasi (2016) & Yes & Yes & Yes & Yes & Yes & No & Yes & Yes & No \\
\hline Singh (2012) & Yes & Yes & Yes & Yes & Yes & No & Yes & Yes & Unclear \\
\hline Khorasanizadeh (2013) & Yes & Yes & Yes & Yes & Yes & No & Yes & No & Unclear \\
\hline
\end{tabular}

Q. 1: Samples were representative?

Q. 2: Participants were appropriately recruited?

Q. 3: Sample size was adequate?

Q. 4: Study subjects and the setting were described?

Q. 5: Data analysis was conducted?

Q. 6: Objective, standard criteria, and reliably were used?

Q. 7: Appropriate statistical analyses were used?

Q. 8: Confounding factors, subgroups, and differences were identified and accounted?

Q. 9: Subpopulations were identified using objective criteria? 
heterogeneity, a fixed-effect model was used. All analyses were performed by the STATA version 12 software (Stata Corp LP, College Station, TX, USA).

\section{Results}

\section{Description of Literature Search}

After searching for all international and domestic databases, 564 articles were found that, after removing repetitive articles, 489 articles were entered into the review phase in terms of title and abstract. After reviewing the titles and abstracts of articles, 57 articles joined to the next stage. At this stage, the full text of the articles was examined and 27 articles considered for the final analysis. In the screening stages of studies, some articles were excluded for a variety of reasons, which included an unrelated topic (327 cases), an unrelated population (31 cases), and repeated results (four cases). The flowchart of the studies was presented in Fig. 1.

\section{Description of Included Studies}

The included studies ${ }^{16-40}$ were published from 1990 to 2016. The main characteristics of the selected studies have been represented in Table 2.

\section{ASIR of Cervix Cancer}

The highest ASIR of CC (4.97 per 100,000) from Golestan province between 2004 and 2010 and the lowest $\operatorname{ASIR}(0.4$ per 100,000) from Ardebil province between 1996 and 1999 was reported.

\section{ASMR of Cervix Cancer}

The highest ASMR of CC $(0.9 .9$ per 100,000) from southern Khorasan province between 2003 and 2005 and the lowest ASMR $(0.4$ per 100,000$)$ from Sistan and Baluchistan province between 2003 and 2005 was reported.

\section{Results of Meta-analysis}

Due to the high heterogeneity of the studies, the random effects model was used. Thus, the ASIR and ASMR of CC in Iran was
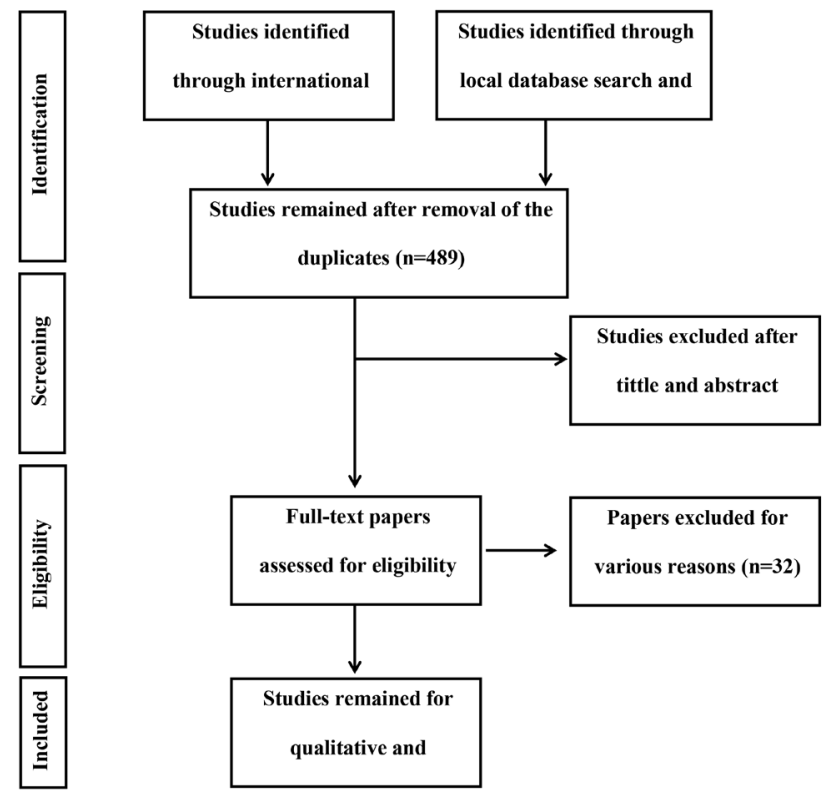

Fig. 1 Flowchart of the included eligible studies in systematic review.

\begin{tabular}{|c|c|c|c|c|}
\hline Author name (year) & Study region & Time period & ASIR & ASMR \\
\hline Saalabian (1990) & Fars & 1985-1989 & 2.30 & - \\
\hline Sadjadi (2003) & Ardabil & 1996-1999 & 0.4 & - \\
\hline Babai (2005) & Semnan & 1998-2002 & 1.08 & - \\
\hline Sadjadi (2005) & Iran (All area) & 2002 & 4.5 & - \\
\hline \multirow[t]{5}{*}{ Fallah (2007) } & Ardabil & $1996-2000$ & 0.93 & - \\
\hline & Gilan & & 1.84 & \\
\hline & Mazandaran & & 2.33 & \\
\hline & Golestan & & 2.76 & \\
\hline & Kerman & & 3.02 & \\
\hline Sadjadi (2007) & Kerman & 1996-2000 & 1.4 & - \\
\hline Mehrabani (2008) & Fars & 1990-2005 & 1.13 & - \\
\hline Somi (2008) & East Azerbaijan & $2006-2007$ & 1.87 & - \\
\hline Mohagheghi (2009) & Tehran & 1998-2001 & 4.8 & - \\
\hline \multirow[t]{5}{*}{ Mousavi (2009) } & Ardabil & 2003-2004 & 1.64 & - \\
\hline & Esfahan & 2004-2005 & 1.90 & \\
\hline & Kerman & $2005-2006$ & 1.90 & \\
\hline & Golestan & & & \\
\hline & Lorestan & & & \\
\hline Mousavi (2009) & Iran (All area) & $2003-2006$ & - & 1.0 \\
\hline Babaei (2009) & Ardabil & $2004-2006$ & 1.4 & - \\
\hline Masoompour (2011) & Fars & $1998-2002$ & 1.5 & - \\
\hline \multirow[t]{6}{*}{ Almasi (2012) } & Fars & $2003-2009$ & 0.87 & - \\
\hline & & & 1.07 & \\
\hline & & & 1.2 & \\
\hline & & & 1.1 & \\
\hline & & & 3.55 & \\
\hline & & & 3.66 & \\
\hline Fateh (2013) & Shahroud & $2002-2010$ & 1.80 & - \\
\hline $\begin{array}{l}\text { Khorasanizadeh } \\
\text { (2013) }\end{array}$ & Iran (All area) & 2007 & 2.47 & - \\
\hline Arab (2014) & Iran (All area) & $\begin{array}{l}2004 \text { and } \\
2008\end{array}$ & $\begin{array}{c}1.71 \\
\text { and } 2.2\end{array}$ & - \\
\hline Arab (2014) & Iran (All area) & 2005 & 1.4 & - \\
\hline Taheri (2014) & Golestan & 2004-2010 & 4.97 & - \\
\hline Sharifian (2014) & Iran (All area) & $2003-2009$ & - & - \\
\hline \multirow[t]{6}{*}{ Rahimi (2015) } & Tehran & 1998-2001 & 1.87 & - \\
\hline & Golestan & 2004-2008 & 2.56 & - \\
\hline & East Azerbaijan & $2006-2007$ & 1.8 & - \\
\hline & Khuzestan & $2002-2009$ & 1.08 & - \\
\hline & Shahroud & $2001-2010$ & & \\
\hline & Semnan & 1998-2002 & & \\
\hline Masoompour (2016) & Fars & $2007-2010$ & 2.55 & - \\
\hline Almasi (2016) & Iran (All area) & 2012 & 2.8 & 1.2 \\
\hline Singh (2012) & Iran (All area) & 2012 & - & 1.0 \\
\hline \multirow{6}{*}{$\begin{array}{l}\text { Khorasanizadeh } \\
\text { (2013) }\end{array}$} & Iran (All area) & 2003-2005 & - & 1.4 \\
\hline & East Azarbaijan & & - & 1.8 \\
\hline & West Azarbaijan & & - & 1.6 \\
\hline & Ardabile & & - & 0.5 \\
\hline & Isfahan & & - & 0.9 \\
\hline & Ilam & & - & 0.9 \\
\hline
\end{tabular}

(Continued) 


\begin{tabular}{|c|c|c|c|}
\hline Author name (year) & Study region & Time period ASIR & ASMR \\
\hline & Bushehr & - & 0.7 \\
\hline & $\begin{array}{l}\text { Charmahal- } \\
\text { bakhtiari }\end{array}$ & - & 0.7 \\
\hline & North Khorasan & - & 1.0 \\
\hline & Khorasan Razavi & - & 0.5 \\
\hline & South Khorasan & - & 1.9 \\
\hline & Khuzestan & - & 1.1 \\
\hline & Zanjan & - & 0.8 \\
\hline & Semnan & - & 0.6 \\
\hline & $\begin{array}{l}\text { Sistanbaluch- } \\
\text { estan }\end{array}$ & - & 0.3 \\
\hline & Fars & - & 1.1 \\
\hline & Ghazvin & - & 1.1 \\
\hline & Ghom & - & 1.2 \\
\hline & $\begin{array}{l}\text { Kohgiluye- } \\
\text { boírahmad }\end{array}$ & - & 0.5 \\
\hline & Kordestan & - & 1.1 \\
\hline & Kermanshah & - & 1.6 \\
\hline & Kerman & - & 0.5 \\
\hline & Golestan & - & 0.6 \\
\hline & Gilan & - & 1.2 \\
\hline & Lorestan & - & 0.5 \\
\hline & Mazandaran & - & 0.8 \\
\hline & Markazi & - & 0.8 \\
\hline & Hormozgan & - & 1.2 \\
\hline & Hamedan & - & 0.6 \\
\hline & Yazd & - & 0.8 \\
\hline
\end{tabular}

2.14 per $100,000,95 \%$ CI (1.89-2.38) and 0.93 per $100,000,95 \%$ CI (0.81-1.05), respectively. The results of the forest plot for incidence and mortality rate are shown in Figs. 2 and 3.

\section{Subgroup Analysis}

Due to the heterogeneity of the results, subgroups were analyzed based on the geographical region. According to the results of the analysis of subgroups, the highest ASIR of CC in the northern region was 2.97 (95\% CI; 2.28-4.14) and the lowest in the northwestern region of the country was $1.28(95 \%$ CI; 0.83-1.73).

The highest ASMR in Northwest provinces was 1.39 (95\% CI; 0.74-2.04) and the lowest in the Southwest was 0.64 (95\% CI; 0.46-0.81)

\section{Meta-regression}

Results of meta-regression manifested a significant association between publication year and ASIR of CC. Thus, year of study is a cause of variability in results (Regression coefficient = $0.038, p=0.011)$. According to the results, an increasing survival rate across the study period was observed.

Due to the limitation of the number of reported years for ASMR, no meta-regression analysis was possible. Results of meta-regression has been shown in Fig. 4.

\section{Publication Bias}

The publication bias among the studies was evaluated using the Egger test. Based on the results, there was no publication bias among the studies (Bias: $6.62,95 \% \mathrm{CI}=-1.79$ to 15.06 ; $p=0.107$ for ASMR, Bias: $3.65,95 \%$ CI $=-5.09$ to 13.91 ; $p=0.443$ for ASIR).

\section{Discussion}

Cancer is the third leading cause of death in Iran (41). There are few studies on the epidemiology of cancer among population of developing countries including Iran. ${ }^{6,10,42-47}$

Based on the findings of this study, the ASIR of CC in Iran was 2.14 and ASMR was 0.93 per 100 000. In a study in Korea, the incidence of CC in the years 1993-2002 has declined from 19.0 to 15.1 per $100,000 .{ }^{48} \mathrm{~A}$ research conducted in India represented that the ASIR of CC was 22.9 per $100,000 .^{49}$

Therefore, as it is observable, the incidence of CC in Iran differs from that of the world as well as in other countries and is at a lower level. One of the possible reasons for this is that the incidence of CC is related to sexual factors, fertility, as well as human papillomavirus, which has a lower prevalence in Islamic countries. ${ }^{20}$ As an example, the overall incidence of female genital cancers in Qatar was 0.9 per $100,000 .{ }^{50}$ In a study on female genital cancers in one of the major provinces of Iran, it was found that the relative frequency of CC in the period of 1391-1394 was declining, and one of the reasons is to perform a screening for early diagnosis of cervical cancer by testing Pap smears in the country. ${ }^{6,51}$

In this study, the highest incidence of CC in the provinces of Golestan and Tehran and its lowest incidence was reported in Ardebil province between 1996 and 1999. According to the studies, changes in the age of marriage, sexual activity at an early age, the number of pregnancies and individual health associated with reproductive organs can be a factor in the incidence of CC. ${ }^{3,51}$ In our country, women are more likely to be married at an early age and have used contraceptive pill for a longer time. On the other hand, the prevalence of hepatitis B infection, which has regional varieties, may affect the incidence of CC. Therefore, the differences between regions can be due to the above-mentioned issues. ${ }^{52}$

The probability of higher diagnostic errors in smaller cities due to less facilities and the possibility of referring patients with ovarian cancer from other provinces to Tehran (for more advanced diagnostic and therapeutic measures) can be effective in increasing the incidence rate in Tehran province.

Based on the results of this study, the mortality rate of this cancer at the age of 45-75 has a steady increase and after age 60 there is a sharp increase, suggesting that people with a higher average age may have a higher incidence of CC. ${ }^{53}$

Accordingly, one of the reasons for the higher mortality of CC in Tehran than other provinces can be attributed to the difference in the mean age of women in these districts. ${ }^{54}$ Another possible contributing factor is the contamination of air. There is a close relationship between air pollution and some of the cancers of women, including breast and cervical cancer. ${ }^{55}$ The results of the study manifest that jobs with low sitting time or low energy consumption are associated with an increase in the incidence of breast, uterine, and ovarian cancer. ${ }^{56}$

\section{Strengths and Limitation of Study}

The strengths of this study is that it is the first study with a wide range on the incidence and mortality of CC in Iran. Its limitations include lack of examination of dissertations, non-electronic, and non-printed sources, as well as the type of studies available in Iran. It should be mentioned that in the previous studies, 


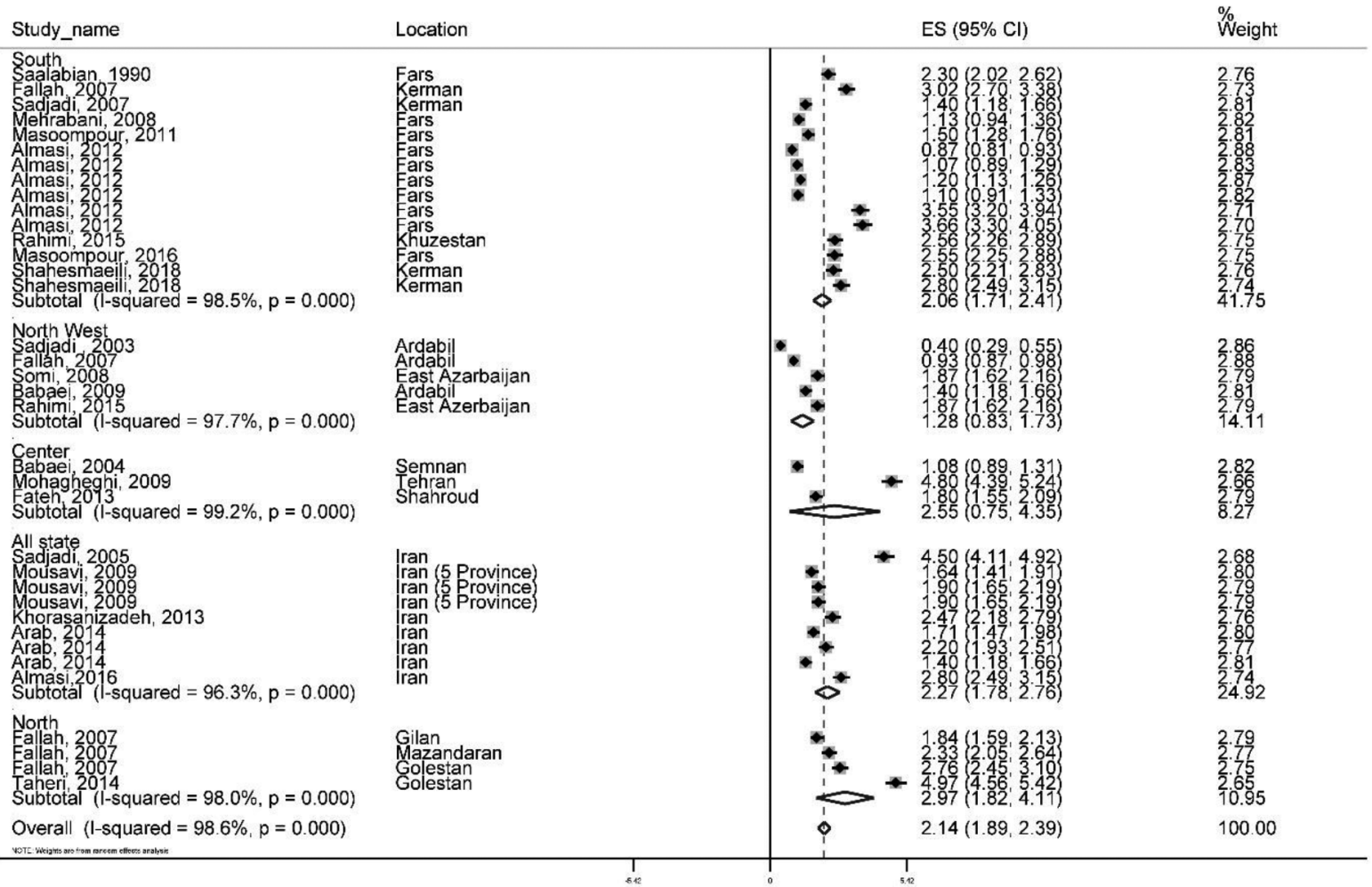

Fig. 2 Forest plot of the random-effect meta-analysis for age standardized incidence rates of cervix cancer in Iran.

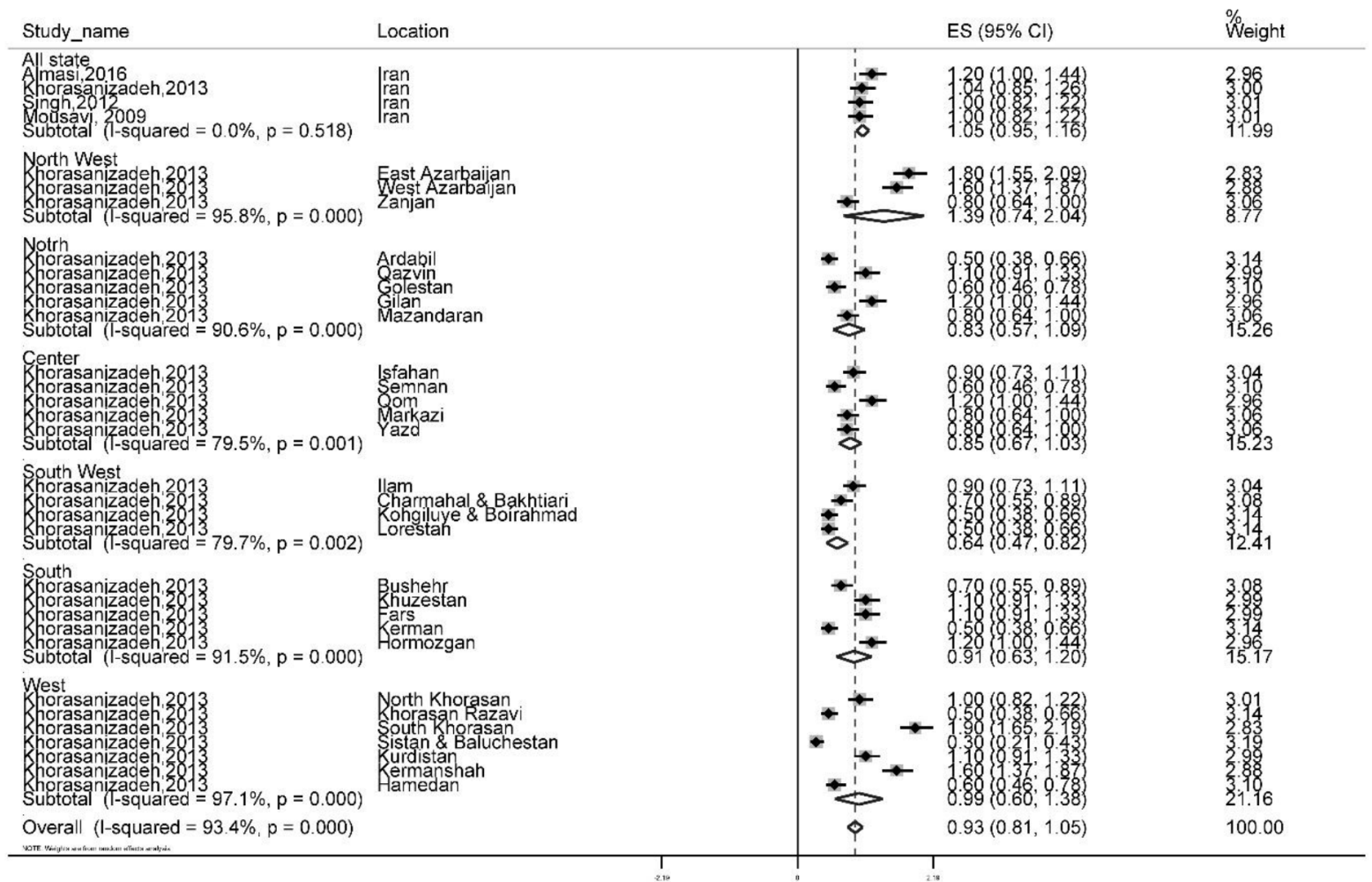

Fig. 3 Forest plot of the random-effect meta-analysis for age standardized mortality rates of cervix cancer in Iran.

CC were diverse, in other words, different studies classified this malignancy in a special way and eventually reported the standardized incidence of age. To give an instance, in some studies, $\mathrm{CC}$ has been reported in general, some have been divided into two or three distinct categories, and in some, only the uterine body cancer has been examined. Therefore, it was not possible to compare the standardized incidence rates reported in all existing studies and it was decided to investigate studies that reported only cancer of the uterus. Another major limitation of our study was the lack of sufficient information on age composition and other information such as sample size and confidence interval that could be used to analyze. 


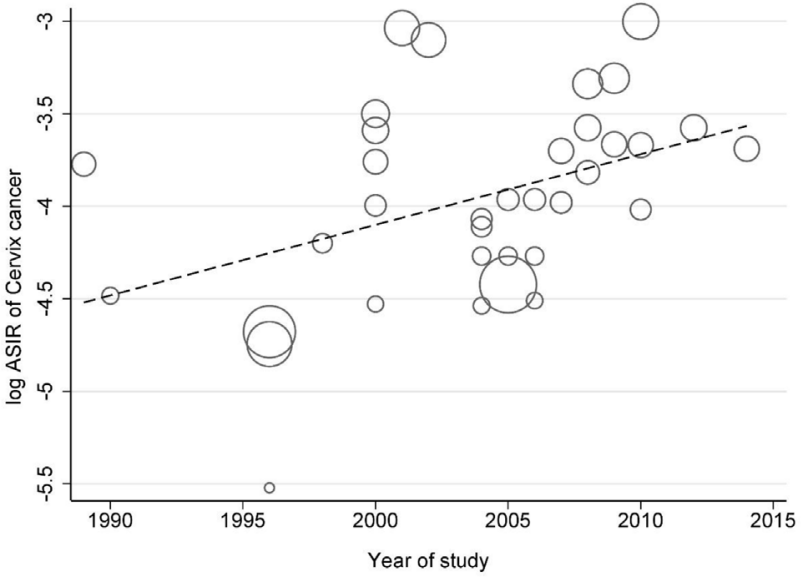

Fig. 4 Meta-regression plots of change in ASIR of cervix cancer according to changes in continuous study moderator's year.

\section{Conclusion}

Overall, according to the findings of this study, the ASIR and ASMR of CC in Iran is lower than in other countries of the world. On the other hand, given the heterogeneity observed in studies in different regions, the interpretation of the results should be more cautious.

\section{Acknowledgments}

This research was supported by the Alborz University of Medical Sciences with the code number 1719-25-02-1396 and the code of ethics Abzums.rec.1396.221.

\section{Conflicts of Interest}

\section{References}

1. Bray F, Ferlay J, Soerjomataram I, Siegel RL, Torre LA, Jemal A. Global cancer statistics 2018: GLOBOCAN estimates of incidence and mortality worldwide for 36 cancers in 185 countries. CA Cancer J Clin. 2018;68:394-424.

2. Weiderpass $E$, Labrèche $F$. Malignant tumors of the female reproductive system. Saf Health Work. 2012;3:166-180.

3. Maheshwari A, Kumar N, Mahantshetty U. Gynecological cancers: A summary of published Indian data. South Asian J Cancer. 2016;5:112-120.

4. Pedersen K, Fogelberg S, Thamsborg LH, Clements M, Nygard M, Kristiansen IS, et al. An overview of cervical cancer epidemiology and prevention in Scandinavia. Acta Obstet Gynecol Scand. 2018;97:795-807.

5. Shrestha AD, Neupane D, Vedsted P, Kallestrup P. Cervical cancer prevalence, incidence and mortality in low and middle income countries: a systematic review. Asian Pac J Cancer Prev. 2018;19:319-324.

6. Mokhtari AM, Riahi S, Fathalipour M, Delam H, Hashemnejad M, Hassanipour S. The age-standardized rate of female genital cancers in Iran: a systematic review and meta-analysis. J Hayat. 2018;24:204-219.

7. Torre LA, Islami F, Siegel RL, Ward EM, Jemal A. Global Cancer in women: burden and trends. Cancer Epidemiol Biomarkers Prev. 2017;26:444-457.

8. Shanta V, Krishnamurthi S, Gajalakshmi CK, Swaminathan R, Ravichandran K. Epidemiology of cancer of the cervix: global and national perspective. J Indian Med Assoc. 2000;98:49-52

9. McGraw SL, Ferrante JM. Update on prevention and screening of cervical cancer. World J Clin Oncol. 2014;5:744-752.

10. Rezaianzadeh A, Mokhtari AM, Hassanipour S, Maghsoudi A, Dehghani SL, Nazarzadeh $\mathrm{M}$, et al. The age-standardized incidence rate of ovarian cancer in iranian women: a systematic review and meta-analysis. Middle East J Cancer. 2018:9:171-178.

11. Naing NN. Easy way to learn standardization : direct and indirect methods. Malays J Med Sci. 2000;7:10-15

12. Funston G, O'Flynn H, Ryan NAJ, Hamilton W, Crosbie EJ. Recognizing gynecological cancer in primary care: risk factors, red flags, and referrals. Adv Ther. 2018;35:577-589.

13. Platz EA. Reducing cancer burden in the population: an overview of epidemiologic evidence to support policies, systems, and environmental changes. Epidemiol Rev. 2017;39:1-10.

14. Momenimovahed Z, Salehiniya H. Cervical cancer in Iran: integrative insights of epidemiological analysis. Biomedicine (Taipei). 2018;8:18.

15. Liberati A, Altman DG, Tetzlaff J, Mulrow C, Gotzsche PC, loannidis JP, et al. The PRISMA statement for reporting systematic reviews and metaanalyses of studies that evaluate healthcare interventions: explanation and elaboration. BMJ. 2009:339:b2700.

16. Almasi-Hashiani A. Farahmand M. Trend of incidence rate for female genital cancers based on cancer registry data in Fars province during 2003-2009. Feyz. 2012;16:353-360 (in Persian).

17. Arab M, Noghabaei G. Comparison of age-standard incidence rate trends of gynecologic and breast cancer in Iran and other countries. Iran J Public Health. 2014:43:1372-1379.

18. Arab M, Noghabaei G, Kazemi SN. Comparison of crude and age-specific incidence rates of breast, ovary, endometrium and cervix cancers in Iran, 2005. Asian Pac J Cancer Prev. 2014;15:2461-2464.
19. Kiadaliri AA. Social disparity in breast and ovarian cancer incidence in Iran, 20032009: A time trend province-level study. J Breast Cancer. 2013;16:372-377.

20. Mohagheghi MA, Mosavi-Jarrahi A, Malekzadeh R, Parkin M. Cancer incidence in Tehran metropolis: the first report from the Tehran populationbased cancer registry, 1998-2001. Arch Iran Med. 2009;12:15-23.

21. Mousavi SM, Gouya MM, Ramazani R, Davanlou M, Hajsadeghi N, Seddighi Z. Cancer incidence and mortality in Iran. Ann Oncol. 2009;20:556-563.

22. Rahimi Z, Kasraei R, Najafi F, Tanhapoor M, Abdi H, Rahimi Z, et al. Cancer notification at a referral hospital of Kermanshah, Western Iran (2006-2009). Asian Pac J Cancer Prev. 2015;16:133-137.

23. Sadjadi A, Malekzadeh R, Derakhshan MH, Sepehr A, Nouraie M, Sotoudeh M, et al. Cancer occurrence in Ardabil: results of a population-based cancer registry from Iran. Int J Cancer. 2003;107:113-118.

24. Sharifian A, Pourhoseingholi MA, Norouzinia M, Vahedi M. Ovarian cancer in Iranian women, a trend analysis of mortality and incidence. Asian Pac J Cancer Prev. 2014;15:10787-10790.

25. Taheri N, Fazel A, Mahmoodzadeh H, Omranpour R, Roshandel G, Gharahjeh $S$, et al. Epidemiology of female reproductive cancers in Iran: results of the gholestan population-based cancer registry. Asian Pac J Cancer Prev. 2014;15:8779-8782

26. Zendehdel K, Sedighi Z, Hassanloo J, Nahvijou A. Audit of a nationwide pathology-based cancer registry in Iran. Basic Clin Cancer Res. 2011;3:7-13.

27. Babai M, Mousavi S, Malek M, Danaie N, Jandaghi J, Tousi J, et al. Survey of cancer incidence during a 5-year (1998-2002) period in Semnan province. Koomesh. 2005;6:237-244

28. Sadjadi A, Nouraie M, Mohagheghi MA, Mousavi-Jarrahi A, Malekezadeh R, Parkin DM. Cancer occurrence in Iran in 2002, an international perspective. Asian Pac J Cancer Prev. 2005;6:359-363.

29. Sadiadi A, Zahedi MJ, Moghadam SD, Nouraie M, Alimohammadian M Ghorbani A, et al. The first population-based cancer survey in Kerman Province of Iran. Iranian J Publ Health. 2007;36:26-34.

30. Somi MH, Farhang S, Mirinezhad SK, Naghashi S, Seif-Farshad M, Golzari M. Cancer in East Azerbaijan, Iran: results of a population-based cancer registry. Asian Pac J Cancer Prev. 2008;9:327-330.

31. Babaei M, Jaafarzadeh H, Sadjadi AR, Samadi F, Yazdanbod A, Fallah M, et al. Cancer incidence and mortality in Ardabil: report of an ongoing population-based cancer registry in Iran, 2004-2006. Iranian J Publ Health. 2009;38:35-45.

32. Masoompour SM, Yarmohammadi H, Rezaianzadeh A, Lankarani KB. Cancer incidence in southern Iran, 1998-2002: Results of population-based cancer registry. Cancer Epidemiol. 2011;35:e42-e47.

33. Fateh M, Emamian MH. Cancer incidence and trend analysis in Shahroud, Iran, 2000-2010. Iran J Cancer Prev. 2013;6:85-94.

34. Masoompour SM, Lankarani KB, Honarvar B, Tabatabaee SH, Moghadami $M$, Khosravizadegan Z. Changing epidemiology of common cancers in Southern Iran, 2007-2010: a cross sectional study. PLoS One. 2016;11:e0155669.

35. Singh GK, Azuine RE, Siahpush M. Global inequalities in cervical cancer incidence and mortality are linked to deprivation, low socioeconomic status, and human development. Int J MCH AIDS. 2012;1:17-30. 
36. Khorasanizadeh F, Hassanloo J, Khaksar N, Taheri SM, Marzaban M, Rashidi $\mathrm{BH}$, et al. Epidemiology of cervical cancer and human papilloma virus infection among Iranian women - Analyses of national data and systematic review of the literature. Gynecol Oncol. 2013;128:277-281.

37. Mehrabani D, Tabei SZ, Heydari ST, Shamsina SJ, Shokrpour N, Amini M, et al. Cancer occurrence in Fars Province, Southern Iran. Iran Red Crescent Med J. 2008;10:314-322.

38. Fallah M. Cancer Incidence in Five Provinces of Iran: Ardebil, Gilan, Mazandaran, Golestan and Kerman, 1996-2000, Tampere University Press, 2007

39. Roshandel G, Boreiri M, Sadjadi A, Malekzadeh R. A diversity of cancer incidence and mortality in west Asian populations. Ann Glob Health. 2014;80:346-357.

40. Salehiniya H, Dashdebi SG, Rafiemanesh H, Mohammadian-Hafshejani A, Enayatrad M. Time trend analysis of cancer incidence in Caspian Sea, 2004-2009: a population-based cancer registries study (northern Iran). Caspian J Intern Med. 2016;7:25-30.

41. Saadat S, Yousefifard M, Asady H, Moghadas Jafari A, Fayaz M, Hosseini M. The Most Important Causes of Death in Iranian Population; a Retrospective Cohort Study. Emerg (Tehran). 2015;3:16-21.

42. Rezaianzadeh A, Hassanipour Azgomi S, Mokhtari AM, Maghsoudi A, Nazarzadeh M, Dehghani SL, et al. The incidence of breast cancer in Iran: a systematic review and meta-analysis. J Anal Oncol. 2016;5:139-145.

43. Hassanipour S, Mokhtari A, Fathalipour M, Salehiniya H. The incidence of lung cancer in Iran: a systematic review and meta-analysis. World Cancer Res J. 2017:4:e980.

44. Rezaianzadeh A, Jalali M, Maghsoudi A, Mokhtari AM, Azgomi SH, Dehghani SL. The overall 5-year survival rate of breast cancer among Iranian women: A systematic review and meta-analysis of published studies. Breast Dis. 2017; 37:63-68.

45. Hassanipour S, Fathalipour M, Salehiniya $\mathrm{H}$. The incidence of prostate cance in Iran: a systematic review and meta-analysis. Prostate Int. 2018;6:41-45.
46. Hassanipour S, Namvar G, Fathalipour M, Salehiniya H. The incidence of kidney cancer in Iran: A systematic review and meta-analysis. BioMedicine (France). 2018;8:22-27.

47. Salehiniya H, Hassanipour S, Mansour-Ghanaei F, Mohseni S, Joukar F,

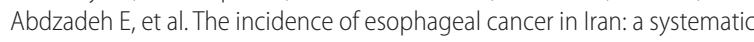
review and meta-analysis. Biomed Res Ther. 2018;5:2493-2503.

48. Chung HH, Jang MJ, Jung KW, Won YJ, Shin HR, Kim JW, et al. Cervical cancer incidence and survival in Korea: 1993-2002. Int J Gynecol Cancer. 2006;16:1833-1838.

49. Yeole BB. Trends in cancer incidence in female breast, cervix uteri, corpus uteri, and ovary in India. Asian Pac J Cancer Prev. 2008;9:119-122.

50. Bener A, Ayub H, Kakil R, Ibrahim W. Patterns of cancer incidence among the population of Qatar: a worldwide comparative study. Asian Pac J Cancer Prev. 2008;9:19-24.

51. Esmaeili R, Ahmadi F, Mohammadi E, Tirgari Seraj A. Life threatening: the most important concern of patients confronting cancer diagnosis. J Hayat. 2013:18:12-22

52. Yang $X$, Cheng Y, Li C. The role of TLRs in cervical cancer with HPV infection: a review. Signal Transduct Target Ther. 2017;2:17055.

53. Chaichian S, Khateri S, Moradi Y, Shadmani FK, Mansori K, Khazaei Z, et al. Trends in cervical cancer incidence in Iran from 2003 to 2009. Middle East J Cancer. 2018:9:57-63.

54. Refaei M, Dehghan Nayeri N, Khakbazan Z, Pakgohar M. Cervical cancer screening in Iranian women: healthcare practitioner perceptions and views. Asian Pac J Cancer Prev. 2017;18:357-363.

55. Keramatinia A, Hassanipour S, Nazarzadeh M, Wurtz M, Monfared AB, Khayyamzadeh $M$, et al. Correlation between nitrogen dioxide as an air pollution indicator and breast cancer: a systematic review and metaanalysis. Asian Pac J Cancer Prev. 2016;17:419-424.

56. Zheng W, Shu XO, McLaughlin JK, Chow WH, Gao YT, Blot WJ. Occupational physical activity and the incidence of cancer of the breast, corpus uteri, and ovary in Shanghai. Cancer. 1993;71:3620-3624. 